\title{
Fetal hemoglobin reactivation and cell engineering in the treatment of sickle cell anemia
}

This article was published in the following Dove Press journal:

Journal of Blood Medicine

2 March 20I I

Number of times this article has been viewed

\author{
Sandro Eridani \\ Andrea Mosca \\ Department of Biomedical \\ Science and Technology, \\ University of Milano, Italy
}

Correspondence: Sandro Eridani Department of Biomedical Science and Technology, University of Milano, Via Fratelli Cervi 93, 20090, Italy

Tel +3902 50330422

$\mathrm{Fax}+390299987559$

Email seridani@gmail.com
Abstract: The natural history of severe hemoglobinopathies like sickle cell disease (SCD) is rather variable, depending on the circumstances, but the main influence on such variability is the level of fetal hemoglobin $(\mathrm{HbF})$ in the patient's red cells. It is well known that a significant $\mathrm{HbF}$ level is associated with a milder course of disease and fewer complications. Therefore, attempts have been made to reactivate using various means the HbF production, which is normally switched off perinatally. A pharmacological approach has been attempted since the $1980 \mathrm{~s}$, ranging from drugs like 5-azacytidine and its derivative, decitabine, to a series of compounds like hydroxyurea and a number of histone deacetylase inhibitors like butyrate, which seem to act as epigenetic modifiers. Many other disparate agents have been tried with mixed results, but hydroxyurea remains the most effective compound so far available. Combinations of different compounds have also been tried with some success. Established treatments like bone marrow or cord blood transplantation are so far the only real cure for a limited number of patients with severe hemoglobinopathies. Improved chemotherapy regimens of milder toxicity than those employed in the past have made it possible recently to obtain a stable, mixed donor-recipient chimerism, with reversal of the SCD phenotype. However, great effort is directed to cell engineering, searching for an effective gene vector by which a desired gene can be transferred into new classes of vectors for autologous hemopoietic stem cells. Recent studies are also aiming at targeted insertion of the therapeutic gene into hemopoietic cells, which can also be "induced" human stem cells, obtained from somatic dedifferentiated cells. Attention in this area must be paid to the possibility of undesired effects, like the emergence of potentially oncogenic cell populations. Finally, an update is presented on improved HbF determination methods, because common international standards are becoming mandatory.

Keywords: sickle cell disease, hemoglobin F, determinants, inducers, cell engineering, induced pluripotent stem cells

\section{Introduction}

In the wide spectrum of congenital hemoglobin disorders, two entities have always attracted attention because of their severity and extensive geographic distribution, ie, beta thalassemia major and sickle cell disease (SCD). In the present review, attention is focused on the latter disease, characterized by a qualitative defect in beta-globin production, due to replacement of a single amino acid (valine for glutamic acid) in the beta-globin chain and formation of an anomalous hemoglobin, called hemoglobin S. This induces severe deformity of red cells upon deoxygenation, hampering microcirculation, and leading to vascular occlusion and critical organ damage. ${ }^{1}$

However, it has been noted that the natural history of this disease shows considerable heterogeneity in signs and symptoms, due to a variety of concomitant situations. 
Actually, the main factor in the variable severity of SCD is the level of fetal hemoglobin $(\mathrm{HbF})$ produced by patients. There are indeed many disparate conditions, in which a higher level of $\mathrm{HbF}$ than expected can be found. They range from hereditary disorders to acquired ones, as well as from blood diseases to nonhematological situations (Table 1). It is well known that populations showing a genetically determined presence of $\mathrm{HbF}$ have a milder form of SCD, including a reduced incidence of severe clinical complications. ${ }^{2}$ It is therefore understandable that many efforts have been directed to restore the production of $\mathrm{HbF}$ in adults. ${ }^{3}$

As for the background of this process, recent studies have produced a good amount of information, particularly on gamma-globin gene control. In the present paper, we therefore propose a brief initial survey of these genetic factors, and then focus on new ways of drug treatment for reactivation of $\mathrm{HbF}$

Table I Conditions affecting hemoglobin F levels

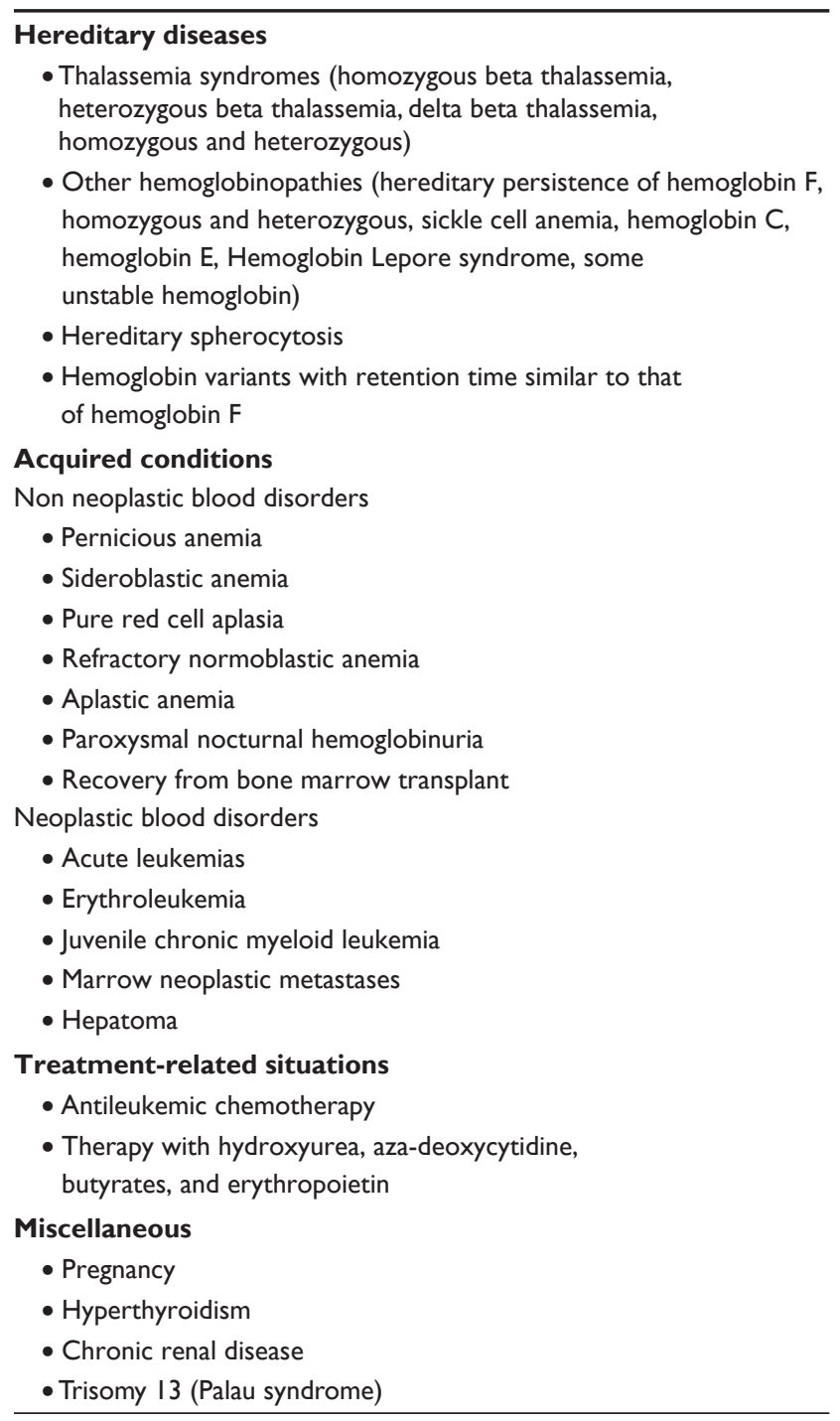

level, as well as attempts at correction of the genetic defect by cell engineering. A brief update on recent methods for $\mathrm{HbF}$ assay is also included.

\section{Genetics of HbF}

It is well known that only a tiny fraction of $\mathrm{HbF}$ is still present in the majority of adults, as a result of the switch to $\mathrm{HbA}$ in early life. However, the switch may be impaired by a number of mutations in the beta-globin cluster, ${ }^{4}$ leading to uniform increase of $\mathrm{HbF}$ (pancellular hereditary persistence of fetal hemoglobin $[\mathrm{HPFH}]$ ), a condition allowing a normal way of life, or to a nonuniform distribution of $\mathrm{HbF}$, based on the coexistence of two populations of red cells, one with a high content of $\mathrm{HbF}$ (so-called F cells) and another with a negligible amount of the same. In this case, the condition is called heterocellular $\mathrm{HPFH}$, which is regarded as a multifactorial quantitative trait, quite distinct from the classical form of pancellular hereditary persistence of fetal hemoglobin. ${ }^{5}$

A number of interesting studies have proposed different mechanisms which may be responsible for such persistence of $\mathrm{HbF}$ in adults, and can be either mutations in critical genic regions involved in the activation of globin genes or deletions of the globin gene cluster. Examples of the former event are single base substitutions in the promoter region of the gamma-globin genes, found in adults with high $\mathrm{HbF}$ production, ${ }^{6}$ or $\mathrm{T}$ to $\mathrm{C}$ substitution in the gamma-globin gene, leading to disruption of the assembly of a repressive chromatin structure, which normally silences the expression of the gamma-globin gene in adult erythrocytes. ${ }^{7}$ In the latter case, (ie, deletional persistence of $\mathrm{HbF}$ ), Gazouli et al, ${ }^{8}$ attempting to explain the production of the $\mathrm{HbF}$ phenotype in adult red cells, carried out an investigation in transgenic mice lacking two elements of the A $\gamma$-to- $\delta$ gene region, suggesting that a deletion of silencer elements in that gene region may account for persistent expression of $\mathrm{HbF}$ in the adult stage. Previous experiments by the same authors had shown that a juxtaposition of downstream enhancers may also contribute to that effect, but different models are not mutually exclusive. According to another study, a downregulation of the transcriptional repressor, ZHX2, or some chromatin remodelling factors may also be involved in deletional hereditary persistence of fetal hemoglobin. ${ }^{9}$ Anyway, there is an obvious benefit from the analysis of multiple mechanisms of $\mathrm{HbF}$ persistence in adults, namely a better understanding of the molecular basis for the perinatal hemoglobin switch.

As far as possible genetic determinants of $\mathrm{HbF}$ production are concerned, recent investigations have produced interesting data (see Table 2). An early hypothesis suggested that variability 
Table 2 Genetic determinants of hemoglobin F production

\begin{tabular}{lc}
\hline Locus & Chromosome \\
\hline$\bullet$ XmnI-HBG2 & II \\
- HMIP (HBSIL-MYB intergenic polymorphism) & 6 \\
- BCLIIA & 2 \\
- OR5 -OR6 (olfactory receptor gene cluster) & II \\
\hline
\end{tabular}

in $\mathrm{HbF}$ was mainly due to independent genetic factors, an effect particularly evident in patients with SCD. ${ }^{10}$ A seminal study showed that a variation of genetic determinants on chromosome $11 \mathrm{p} 16$ was involved in the expression of $\mathrm{HbF}$, and precisely at position $158 .{ }^{11}$ However, the effect of such variation is modest in normal people, and its presence is not always associated with high $\mathrm{HbF}$, but variants at this locus have a considerable frequency in certain populations like Asian Indians, in whom it was first studied and found to be associated with the presence of moderate levels of $\mathrm{HbF}$ in normal individuals. ${ }^{12}$

A second determinant was found in a large Indian family with beta thalassemia and hereditary persistence of fetal hemoglobin, situated in a region on chromosome 6q23-q24, between the HBS1L and MYB genes. ${ }^{13}$ This locus was therefore termed HMIP (HBS1L-MYB intergenic polymorphism), and is an important component (about 19\%) of the F cell trait in the general population.

A strong association with $\mathrm{HbF}$ level was eventually observed with a third locus, situated on chromosome $2 \mathrm{p} 15$, namely the BCL11A, leading to the hypothesis that a product of this locus, a multizinc finger transcription factor, may encode a stage-specific regulator of $\mathrm{HbF}$ expression. ${ }^{14} \mathrm{On}$ the clinical side, extensive research carried out among patients in Sardinia and other groups showed that a variant of BCL11A was strongly associated with individuals having high $\mathrm{HbF}$ levels, as well as with patients having mild forms of thalassemia and SCD. ${ }^{15} \mathrm{~A}$ very recent study, based on genome-wide association, has also identified a regulatory region in the olfactory receptor gene cluster (on chromosome 11), which may play a role in gamma-globin gene expression. ${ }^{16}$

Finally, it should be stressed that, although recent progress in the genetics of $\mathrm{HbF}$ has not yet promoted therapeutic applications, every contribution to the understanding of genetic mechanisms presiding over $\mathrm{HbF}$ synthesis and to the $\mathrm{HbF}-$ to-HbA switch is a necessary premise for the formulation of treatment strategies for severe hemoglobin disorders.

\section{Inducers of fetal hemoglobin}

Agents capable of inducing production of fetal hemoglobin have been known for many years, and have also been used in clinical trials (Table 3).
Table 3 Inducers of hemoglobin $\mathrm{F}$ production

- Nucleoside analogs, ie, azacytidine and decitabine

- Hydroxyurea (hydroxycarbamide)

- Histone deacetylase inhibitors, ie, butyrate, trychostatin A, apicidin, scriptaid, hydroxyamides

- Others, including erythropoietin, valproate, thalidomide derivatives, kit ligand

1) It was in the early 1980 s that 5 -azacytidine was shown to be able to reinduce production of $\mathrm{HbF}$ in adults, as well as in experimental animals. A few patients with beta thalassemia and SCD treated with this drug showed a modest correction of globin chain imbalance and had lower transfusion needs. ${ }^{17}$ However, the possibility that such treatment could have an oncogenic effect discouraged the undertaking of these trials. It was only years later that a derivative of azacytidine, namely deoxy-azacytidine, or decitabine, was found to be effective in reactivating production of fetal hemoglobin, and was therefore started in regular trials on SCD patients. ${ }^{18}$ As for possible toxic effects from this drug, only reversible neutropenia was observed, while tests on experimental animals not only showed absence of tumorigenic action, but even suggested a decrease of tumor formation in mice predisposed to cancer. ${ }^{19}$

Parenteral administration of decitabine can produce a notable increase of $\mathrm{HbF}$ levels as well as stimulate erythroid differentiation in SCD patients. ${ }^{20}$ Oral preparations have also been tested in animals, with the aim of making them more acceptable to patients. ${ }^{21}$ More investigations are needed to study possible long-term adverse effects of this compound.

Great interest was devoted to the study of the mechanism of action of different compounds in the induction of HbF. Early suggestions of a relevant effect on DNA hypomethylation at the promoters of the gamma-globin gene ${ }^{3}$ were followed by the realization that different mechanisms may be involved. A unifying theory has been proposed, based on the assumption that a variety of cellular stresses and stimuli can promote coordinated stress responses, including gamma-globin gene activation. Different signaling pathways, like cAMP, p38MAPK, and others may be involved. ${ }^{22}$

2) Hydroxyurea (hydroxycarbamide $[\mathrm{HC}]$ ) has been known for a long time as a well tolerated oral treatment for some myeloproliferative disorders. Its action on $\mathrm{HbF}$ production, first observed in baboons, was then tested and demonstrated in clinical trials on SCD patients. Predictably, bone marrow suppression was observed after long-term treatment, but this effect was reversible. ${ }^{3}$ The mechanism of action of this compound seems to be mediated through the induction of a GTP-binding protein SAR, which modulates expres- 
sion of the gamma-globin gene in erythroid cells. ${ }^{23}$ Very good results have been reported recently in a 17-year trial carried out in a variety of sickle cell syndromes. A dramatic reduction of severe pain crises, transfusion requirements and hospital admissions was obtained, showing how prolonged and tolerable treatment with hydroxyurea can profoundly modify the natural history of the disease. ${ }^{24}$

As for the mechanism of action of hydroxyurea, a series of investigations point to an effect on genes which are involved in hemoglobin synthesis. One of these genes is the transcription factor, EGR1, which is one of the most upregulated genes following $\mathrm{HC}$ treatment. Another group of genes, represented by CENTB1 (centaurin, beta 1), ARHGAP4 (Rho GTPase activating protein 4), and RIN3 (Ras and Rab interactor 3), were found to be induced after hydroxyurea administration. ${ }^{25}$ Another study, carried out in reticulocytes from SCD patients after hydroxyurea treatment showed an altered expression of genes associated with the regulation of globin expression, like SUD53, FZD5, and PHC3 ${ }^{26}$ These results show that hydroxyurea produces significant changes in the gene expression pattern, with activation of transcription factors and pathways involved in signal transduction, eventually leading to an increase of globin gene expression.

The search continues to find agents able to enhance the action of hydroxyurea in SCD patients. In this context, a compound which has been known for a long time as an $\mathrm{HbF}$ inducer is erythropoietin, which is capable of increasing the amount of $\mathrm{F}$ cells and $\mathrm{HbF}$ concentration. A synergistic action was seen when erythropoietin was associated with hydroxyurea, either simultaneously or sequentially, and of special interest is the finding of a good erythropoietin response in patients who were hydroxyurea-intolerant. In this case, erythropoietin treatment made it possible to tolerate hydroxyurea dosage escalation, with an increase in F cells and only minor side effects. ${ }^{27}$ More studies are in progress to investigate the potential of such a drug combination.

3) Butyrate was the earliest of a number of compounds used in this context because of their action as inhibitors of histone deacetylase. It is indeed known that by promoting histone acetylation, butyrate increases the transcription rate of the gamma-globin gene, as well as the translation of gamma-globin mRNA. ${ }^{28}$ It has also been demonstrated that transcription factors like GATA1 and NF-E32 are involved. ${ }^{29}$

Other histone deacetylase inhibitors, and butyrate itself, have also shown a different mechanism of action, namely through activation of the p38MAP kinase pathway. The effector molecules have been identified by Sangerman et al as CREB1 and ATF2, acting via the aforementioned pathway, which therefore appears to be one of the main mediators of gammaglobin gene regulation. ${ }^{30}$ Many more compounds, acting as histone deacetylase inhibitors, have been mentioned as beneficial agents in sickle cell disease. ${ }^{31}$

New classes of synthetic histone deacetylase inhibitors, defined as aroyl-pyrrolyl hydroxyamides and uracil-based hydroxyamides, have also been tested. Of 24 agents, two were found to be active for their ability to induce $\mathrm{HbF}$ in different models of erythroid differentiation. The two compounds increased the $\gamma /(\gamma+\beta)$ ratio in normal erythroid cells. Interestingly, both compounds were also effective in correcting the impaired in vitro maturation of beta thalassemic erythroblasts. ${ }^{32}$ These results and those obtained with other types of histone deacetylase inhibitors seem to suggest that compounds acting as epigenetic modifiers, namely capable of modulating gene expression, may be a promising area of investigation.

4) A number of disparate compounds has been suggested as endowed with stimulating activity on the production of gamma-globin and $\mathrm{HbF}$. One of them is valproate, which was found to induce hemoglobin synthesis in erythroid cells, again by activation of the $\mathrm{p} 38$ pathway. ${ }^{33}$

An interesting compound tried in this context is the kit ligand, an important cytokine for the initiation of hemopoiesis. In unilineage erythroid cultures of 20 patients with major beta thalassemia or thalassemia intermedia, addition of kit ligand induced a marked increase of gamma-globin synthesis, thus reaching $\mathrm{HbF}$ levels three-fold higher than in control

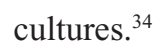

Worth mentioning is the effect of thalidomide, which seems capable of inducing $\mathrm{HbF}$ expression via activation of the same p38MAPK signaling pathway, as well as the action of two thalidomide analogs, used as immunomodulators, which have been shown to possess, among other well known activities, a stimulating effect on $\mathrm{HbF}$ production. Such compounds, ie, pomalidomide and lenalinamide, recently tested on early erythroid progenitors in vitro, caused increased proliferation of immature erythroid cells, regulated hemoglobin transcription, and induction of $\mathrm{HbF}$ without cytotoxicity. A synergistic effect was also observed in association with hydroxyurea. ${ }^{35}$

\section{Cell transplant and cell engineering}

An effective strategy employed in SCD is the transplantation of hemopoietic bone marrow or cord blood, thus delegating to transplanted stem cells the task of providing normal levels of hemoglobin A. However, it has been calculated that, up 
to 2008 , more than 1600 allogeneic transplants had been performed in beta thalassemia, but many fewer were done in SCD, perhaps because fewer patients in the advanced stages were eligible, due to the presence of severe vascular damage. ${ }^{36}$

This option is moreover restricted by limited availability of suitable donors and the severe effects of marrow ablation treatment, including reduced fertility, especially in women. To overcome such limitations, unrelated donors have been used with some success and nonablative regimens have also been employed, while, in order to preserve reproductive potential in women, ovarian tissue preservation and subsequent implantation have been employed, obtaining successful embryo development. ${ }^{37}$

More recently, sophisticated strategies, based on cell engineering, have been developed to transfer correcting genes in patients with a single gene defect. It is certainly fair to mention some remarkable success obtained by gene therapy in genetic immunodeficiency diseases. ${ }^{38}$ As far as SCD is concerned, a search has been going on for a long time to find an effective gene vector which would allow transfer of a desired gene into hemopoietic stem cells. After early attempts using gamma retroviral vectors to transduce globin genes into dividing stem cells, ${ }^{39}$ lentiviral vectors, a subclass of retroviruses capable of transducing not only proliferating but also quiescent cells, proved more effective. ${ }^{40}$ It has been stressed that lentiviral vectors should be erythroid-specific, differentiation- and stage-restricted, position-independent, and sustainable over time. ${ }^{41}$

This approach can be adopted for SCD, forcing the expression of fetal hemoglobin, which, even at low concentration, has been shown to exert a potent antisickling effect. ${ }^{42} \mathrm{On}$ the other side, it has been noted that gene therapy for SCD, to be effective, should induce a therapeutic gene in the greatest part of the red cell population, because even a small proportion of remaining sickle cells may cause vaso-occlusion and severe ischemia. ${ }^{43}$

As for the cell type to be used for such correction, the most primitive progenitors, namely embryonic stem cells, were used initially in mice with SCD by the technique of gene targeting and homologous recombination. ${ }^{44}$ The clinical limitation of this procedure is at present the restriction on human embryonic stem cell research. However, great attention has been devoted recently to a special class of hemopoietic stem cells, which can be used for cell engineering, namely induced pluripotent stem cells, which can be obtained by reprogramming somatic cells and restoring the potential to develop new differentiated cells. ${ }^{45}$
However, many questions are still unsolved about possible applications of human induced pluripotent stem cells in cell engineering and regenerative medicine, like the permanence of foreign DNA in the host genome. New techniques have therefore been developed to remove the integrated DNA from the genome of induced pluripotent stem cells, ${ }^{46}$ making them safer for clinical use.

It is apparent that a number of modalities are now available to try to modify the genetic defects in hemoglobinopathies, including the sickle mutation. This brings to the forefront the issue of safety requirements in gene therapy. It is indeed well known that, in a few cases of genetic immunodeficiency, a neoplastic proliferation was triggered by insertional mutagenesis of a proto-oncogene, raising the possibility that recombinant retroviral vectors could influence the expression of nearby genes. ${ }^{47}$ Although gamma-globin gene vectors seem less prone to induce the expression of dangerous genes, this is a problem which requires great attention and is presently the object of intensive research.

\section{Progress in methods for fetal hemoglobin determination}

Unfortunately, there is no international standardization program for $\mathrm{HbF}$, and no quality specifications have been reported so far, although these are available for glycated hemoglobin and total hemoglobin. Therefore, it is important to outline criteria used for measurement units and the reference interval for the expression of $\mathrm{HbF}$. A uniform measurement unit, used worldwide, is the relative percentage of total hemoglobin, although this is not in line with the international SI system. Every professional laboratory should build its own reference interval, by measuring $\mathrm{HbF}$ in at least 100 adults, who are not iron-depleted and not carriers of alpha or beta thalassemia.

It is generally assumed that $\mathrm{HbF}$ above $1 \%$ in a healthy adult individual could be due either to a genetic defect or to some acquired condition. A review on this topic has been proposed recently as a guide for the interpretation of clinical $\mathrm{HbF}$ data and a valuable aid to correct diagnosis. ${ }^{48}$

Among the more sophisticated methods for the assessment of $\mathrm{HbF}$ levels, we may include the determination of single nucleotide polymorphisms, whose variations have received wide application in molecular genetics. ${ }^{49}$ It is to be expected that studies of genomic regions associated with $\mathrm{HbF}$ levels will provide interesting indications for the diagnosis and perhaps the therapeutic approach to hemoglobinopathies. 


\section{Future directions}

- Identification of the full set of genes controlling gammaglobin synthesis and $\mathrm{HbF}$ production

- Optimization of the efficacy of compounds already used for activating $\mathrm{HbF}$ production and exploration of new drug combinations

- Reduction of the risk-benefit ratio of stem cell transplants, making it possible to treat a larger number of patients

- Attempt to translate gene therapy from the experimental arena to clinical reality, keeping into account its dangers and limitations.

The first point implies further efforts along a pathway which has already produced promising results. It has been stressed, however, that only about half of the genetic factors influencing $\mathrm{HbF}$ control has been identified and that multiple loci, perhaps of limited relevance, still have to be located. ${ }^{5}$ Environmental factors also await to be clarified and in this context more comparisons between affected populations in different parts of the world and groups exposed to different life situations should be profitable..$^{50}$

As for the second point, the list of compounds which have been proposed as therapeutic agents is quite impressive, but so far hydroxyurea is the only one subjected to extensive clinical trials and shown to produce satisfactory results, although not in all cases. More research is needed to elucidate the mechanism of action of hydroxyurea and the other compounds, because a better pharmacological treatment will reduce the need for the most difficult and expensive forms of therapy. More combination treatments will undoubtedly be tried (keeping hydroxyurea as the main component) with the aim to formulate the best scheme for any individual patient, according to age, gender, and severity of disease. Further investigations will also be centered on practical aspects of drug presentation, eg, the possibility to give decitabine in an oral form, ${ }^{21}$ which has been already tried in monkeys and is likely to prove more acceptable in human patients.

Stem cell transplantation is commonly considered the only curative treatment for SCD and, as such, is receiving special attention. A number of reports have highlighted the problems involved using reduced intensity preparative regimens for treating these patients and many failures have been reported, due in most cases to lack of sustained donor engraftment. ${ }^{51}$ However, in a recent study of nonmyeloablative allogeneic hematopoietic stem cell transplantation, including total body irradiation and treatment with immune suppressors, a stable, mixed donor recipient chimerism was achieved, with reversal of the sickle cell phenotype..$^{52}$
Furthermore, in addition to "technical" problems, there is a daunting issue of ethical impact pending on hemopoietic stem cell transplantation, namely the opportunity of giving birth to a sibling in order to provide a suitable donor for a severely affected child. The morality of this practice has been indeed questioned, particularly if programming a donor is performed exclusively as a utilitarian operation..$^{53}$

The problems involved in gene therapy designs are still a great challenge and more research is certainly needed. As for human trials, worries have been raised very recently, because it was shown that a patient with beta thalassemia, treated successfully with a lentivirus-modified beta-globin gene in 2007 , and presently transfusion-free, now produces about $10 \%$ of blood cells with an insertion which may give a growth advantage and thus tumorigenic potential..$^{54}$

One area of investigation is therefore the search for new types of vectors, possibly nonviral. In this respect, it is worthwhile to mention very recent progress obtained using biodegradable polymeric vectors, and a class of these vectors has recently been developed and optimized for high transfection efficiency. ${ }^{55}$ This may encourage more investigation along this line.

Further developments are awaited following the previously quoted attempts to correct the SCD mutation by homologous recombination. Actually, this procedure, proposed earlier in a mouse model, ${ }^{56}$ was performed recently in a patient with beta thalassemia, with skin fibroblasts removed, transformed into pluripotent stem cells, and then differentiated into hemopoietic stem cells, capable of producing normal adult hemoglobin. It was even suggested to collect cells from amniotic fluid or chorionic villus sampling, used for prenatal diagnosis, reprogram them into induced pluripotent stem cells, correct the mutation, and reinfuse them during the perinatal period, ie, an option for very early treatment before organ damage takes place. ${ }^{57}$

As for the tools necessary to introduce specific changes into the genome of patient-derived induced pluripotent stem cells, a recent approach is based on zinc finger nuclease technology, which enables targeting of a specific DNA binding domain to a preselected chromosomal site. ${ }^{58,59}$ Both approaches allowed the introduction of defined genetic modifications in highly sensitive induced pluripotent stem cells, without reported side effects on the pluripotency of these cells or their genetic stability.

Mention was made before of an encouraging improvement obtained with severe thalassemia by gene therapy. ${ }^{54}$ However, as far as SCD is concerned, 100 years have passed since the first description of the disease and, despite 
remarkable progress in the knowledge of pathogenetic and clinical aspects, a consistently effective treatment remains elusive and requires further investigations. ${ }^{60}$

\section{Acknowledgment}

We are grateful to Miss Milena Tozzi at the University of Milano for assistance in revising the literature and for editing the manuscript. Work partially supported by a grant from the Ministry of University and Research (M.I.U.R PRIN 2008, A.M. recipient)

\section{Disclosure}

The authors report no conflicts of interest in this work.

\section{References}

1. Serjeant GR, Serjeant BE. Sickle cell disease. 3rd ed. Oxford: Oxford University Press; 2001.

2. Platt OS, Brambilla DJ, Rosse WF, et al. Mortality in sickle cell disease. Life expectancy and risk factors for early death. N Engl J Med. 1994; 330:1639-1644.

3. Fathallah H, Atweh GF. Induction of fetal hemoglobin in the treatment of sickle cell disease. Hematology Am Soc Hematol Educ Program. 2006;58-62.

4. Karlsson S, Nienhuis AW. Developmental regulation of human globin genes. Annu Rev Biochem. 1985;54:1071-1108.

5. Thein SL, Menzel S, Lathrop M, Garner C. Control of fetal hemoglobin: New insights emerging from genomics and clinical implications. Hum Mol Genet. 2009;18:R216- R223.

6. Tasiopoulou M, Boussiou M, Sinopoulou K, Moraitis G, LoutradiAnagnostou A, Karababa P. ${ }^{\mathrm{G}} \gamma-196 \mathrm{C} \rightarrow \mathrm{T},{ }^{\mathrm{A}} \gamma-201 \mathrm{C} \rightarrow \mathrm{T}$ : Two novel mutations in the promoter region of the $\gamma$-globin genes associated with nondeletional hereditary persistence of fetal hemoglobin in Greece. Blood Cells Mol Dis. 2008;40:320-322.

7. Liu LR, Du ZW, Zhao HL, et al. T to C substitution at -175 or -173 of the gamma-globin promoter affects GATA-1 and Oct-1 binding in vitro differently but can independently reproduce the hereditary persistence of fetal hemoglobin phenotype in transgenic mice. $J$ Biol Chem. 2005;280:7452-7459.

8. Gazouli M, Katsantoni E, Kosteas T, Anagnou NP. Persistent fetal gamma-globin expression in adult transgenic mice following deletion of two silencer elements located $3^{\prime}$ to the human gamma-globin gene. Mol Med. 2009;15:415-424.

9. De Andrade TG, Peterson KR, Cunha AF, et al. Identification of novel candidate genes for globin regulation in erythroid cells containing large deletions of the human $\beta$-globin gene cluster. Blood Cells Mol Dis. 2006;37:82-90.

10. Gilman JG, Huisman TH. Two independent genetic factors in the betaglobin gene cluster are associated with high $\mathrm{G}$ gamma-levels in the $\mathrm{HbF}$ of SS patients. Blood. 1984;64:452-457.

11. Ballas SK, Talacki CA, Adachi K, Schwartz E, Surrey S, Rappaport E. The Xmn I site ( $-158, \mathrm{C}-\mathrm{T}) 5^{\prime}$ to the $\mathrm{G}$ gamma gene: Correlation with the Senegalese haplotype and G gamma globin expression. Hemoglobin. 1991;15:393-405.

12. Sampietro M, Thein SL, Contreras M, Pazmany L. Variation of HbF and F-cell number with the G-gamma Xmn I (C-T) polymorphism in normal individuals. Blood. 1992;79:832-833.

13. Garner C, Mitchell J, Hatzis T, Reittie J, Farrall M, Thein SL. Haplotype mapping of a major quantitative-trait locus for fetal hemoglobin production, on chromosome 6q23. Am J Hum Genet. 1998;68:1468-1474.

14. Menzel S, Garner C, Gut I, et al. A QTL influencing F cell production maps to a gene encoding a zinc-finger protein on chromosome $2 \mathrm{p} 15$. Nat Genet. 2007;39:1197-1199.
15. Uda M, Galanello R, Sanna S, et al. Genome-wide association study shows BCL11A associated with persistent fetal hemoglobin and amelioration of the phenotype of beta-thalassemia. Proc Natl Acad Sci U S A. 2008; 105:1620-1625.

16. Solovieff N, Milton JN, Hartley SW, et al. Fetal hemoglobin in sickle cell anemia: Genome-wide association studies suggest a regulatory region in the $5^{\prime}$ olfactory receptor gene cluster. Blood. 2010;115: $1815-1822$.

17. Charache S, Dover G, Smith K, Talbot CC Jr, Moyer M, Boyer S. Treatment of sickle cell anemia with 5-azacytidine results in increased fetal hemoglobin production and is associated with nonrandom hypomethylation of DNA around the gamma-delta-beta-globin gene complex. Proc Natl Acad Sci U S A. 1983;80:4842-4846.

18. Koshy M, Dorn L, Bressler L, et al. 2-deoxy 5-azacytidine and fetal hemoglobin induction in sickle cell anemia. Blood. 2000;96: 2379-2384.

19. Belinsky SA, Klinge DM, Stidley CA, et al. Inhibition of DNA methylation and histone deacetylation prevents murine lung cancer. Cancer Res. 2003;63:7089-7093.

20. Saunthararajah Y, Hillery CA, Lavelle D, et al. Effects of 5-azadeoxycytidine on fetal hemoglobin levels, red cell adhesion, and hematopoietic differentiation in patients with sickle cell disease. Blood. 2003; $102: 3865-3870$.

21. Lavelle D, Chin J, Vaitkus K, et al. Oral decitabine reactivates expression of the methylated $\gamma$-globin gene in Papio anubis. Am J Hematol. 2007;82:981-985.

22. Mabaera R, West RJ, Conine SJ, et al. A cell stress signaling model of fetal hemoglobin induction: what doesn't kill red blood cells may make them stronger. Exp Hematol. 2008;36:1057-1072.

23. Tang DC, Zhu J, Liu W, et al. The hydroxyurea-induced small GTPbinding protein SAR modulates gamma-globin gene expression in human erythroid cells. Blood. 2005;106:3256-3263.

24. Voskaridou E, Christoulas D, Bilalis A, et al. The effect of prolonged administration of hydroxyurea on morbidity and mortality in adult patients with sickle cell syndromes: Results of a 17-year, single center, trial (LaSHS). Blood. 2010;115:2354-2363.

25. Costa FC, da Cunha AF, Fattori A, et al. Gene expression profiles of erythroid precursors characterise several mechanisms of the action of hydroxycarbamide in sickle cell anaemia. $B r J$ Haematol. 2007;136:333-342.

26. Moreira LS, de Andrade TG, Albuquerque DM, et al. Identification of differentially expressed genes induced by hydroxyurea in reticulocytes from sickle cell anaemia patients. Clin Exp Pharmacol Physiol. 2008;35:651-655.

27. Little JA, McGowan VR, Kato GJ, et al. Combination erythropoietinhydroxyurea therapy in sickle cell disease: experience from the National Institutes of Health and a literature review. Haematologica. 2006;91: 1076-1083.

28. Weinberg RS, Ji X, Sutton M, et al. Butyrate increases the efficiency of translation of -globin mRNA. Blood. 2005;105: 1807-1809.

29. Chenais B. Requirement of GATA-1 and p45 NF-E2 expression in butyric acid-induced erythroid differentiation. Biochem Biophys Res Commun. 1998;253:883-886.

30. Sangerman J, Lee MS, Yao X, et al. Mechanism for fetal hemoglobin induction by histone deacetylase inhibitors involves gamma-globin activation by CREB1 and ATF-2. Blood. 2006;108: 3590-3599.

31. Ataga KI. Novel therapies in sickle cell disease. Hematology Am Soc Hematol Educ Program. 2009;54-60.

32. Mai A, Jelicic K, Rotili D, et al. Identification of two new synthetic histone deacetylase inhibitors that modulate globin gene expression in erythroid cells from normal donors and thalassemic patients. Mol Pharmacol. 2007;72:1111-1123.

33. Witt O, Mönkemeyer S, Kanbach K, Pekrun A. Induction of fetal hemoglobin synthesis by valproate: Modulation of MAP kinase pathways. Am J Hematol. 2002;7:45-46. 
34. Gabbianelli M, Morsilli O, Massa A, et al. Effective erythropoiesis and $\mathrm{HbF}$ reactivation induced by kit ligand in $\beta$-thalassemia. Blood. 2008; 111:421-429.

35. Moutouh-de Parseval LA, Verhelle D, Glezer E, et al. Pomalidomide and lenalidomide regulate erythropoiesis and fetal hemoglobin production in human CD34+ cells. J Clin Invest. 2008;118:248-258.

36. Bathia M, Walters MC. Haematopoietic cell transplantation for thalassemia and sickle cell disease: Past, present and future. Bone Marrow Transplant. 2008;4:109-117.

37. Oktay K, Buyuk E, Veeck L, et al. Embryo development after heterotopic transplantation of cryopreserved ovarian tissue. Lancet. 2004;363:837-840.

38. Aiuti A, Cattaneo F, Galimberti S, et al. Gene therapy for immunodeficiency due to adenosine-deaminase deficiency. N Engl J Med. 2009; 360:447-458.

39. Karlsson S, Bodine DM, Perry L, Papayannopoulou T, Nienhuis AW. Expression of the human beta-globin gene following retroviral-mediated transfer into multipotential hematopoietic progenitors of mice. Proc Natl Acad Sci U S A. 1988;16:6062-6066.

40. May C, Rivella S, Callegari J, et al. Therapeutic haemoglobin synthesis in beta-thalassaemic mice expressing lentivirus-encoded human beta globin. Nature. 2000;406:82-86.

41. Sadelain M, Boulad F, Lisowski L, Moi M, Riviere I. Stem cell engineering for the treatment of severe haemoglobinopathies. Curr Mol Med. 2008;8:690-697.

42. Bunn HF. Induction of fetal hemoglobin in sickle cell disease. Blood. 1999;93:1787-1789.

43. Persons DA, Tisdale JF. Gene therapy for the hemoglobin disorders. Semin Hematol. 2004;41:279-286.

44. Chang JC, Ye L, Kan YW. Correction of the sickle cell mutation in embryonic stem cells. Proc Natl Acad Sci US A. 2006;103:1036-1040.

45. Takahashi K, Yamanaka S. Induction of pluripotent stem cells from mouse embryonic and adult fibroblast cultures by defined factors. Cell. 2006;126:663-676.

46. Kaji K, Norrby K, Paca A, Mileikovsky M, Mohseni P, Woltjen K. Virus-free induction of pluripotency and subsequent excision of reprogramming factors. Nature. 2009;458:771-775.

47. Hacein-Bey-Abina S, Garrigue A, Wang GP, et al. Insertional oncogenesis in 4 patients after retrovirus-mediated gene therapy of SCID-X1. $J$ Clin Invest. 2008;118:3132-3142.
48. Mosca A, Paleari R, Leone D, Ivaldi G. The relevance of hemoglobin F measurement in the diagnosis of thalassaemias and related hemoglobinopathies. Clin Biochem. 2009;42:1797-1801.

49. Long AD, Langley $\mathrm{CH}$. The power of association studies to detect the contribution of candidate genetic loci to variation in complex traits. Genome Res. 1999;9:720-731.

50. Creary LE, Ulug P, Menzel S, et al. Genetic variation on chromosome 6 influences $\mathrm{F}$ cell levels in healthy individuals of African descent and HbF levels in sickle cell patients. PLoS One. 2009;4: e4218.

51. Locatelli F. Reduced-intensity regimens in allogeneic hematopoietic stem cell transplantation for hemoglobinopathies. Hematology Am Soc Hematol Educ Program. 2006;398-401.

52. Hsieh MM, Kang EM, Fitzhugh CD, et al. Allogeneic hematopoietic stem-cell transplantation for sickle cell disease. N Engl J Med. 2009; 361:2309-2317.

53. Burgio GR, Locatelli F. Programming of a haemopoietic stem cell donor: The evolution of a project over time. Haematologica. 2006;91: 1015-1016.

54. Cavazzana-Calvo M, Payen E, Negre O, et al. Transfusion independence and HMGA2 activation after gene therapy of human $\beta$-thalassaemia. Nature. 2010;467:318-322.

55. Yang F, Green JJ, Dinio T, et al. Gene delivery to human adult and embryonic cell-derived stem cells using biodegradable nanoparticulate polymeric vectors. Gene Ther. 2009;16:533-546.

56. Hanna J, Wernig M, Markoulaki S, et al. Treatment of sickle cell anemia mouse model with iPS cells generated from autologous skin. Science. 2007:318:1920-1923.

57. Ye L, Chang JC, Lin C, Sun X, Yu J, Kan YW. Induced pluripotent stem cells offer new approach to therapy in thalassemia and sickle cell anemia and option in prenatal diagnosis in genetic diseases. Proc Natl Acad Sci U S A. 2009;106:9826-9830.

58. Zou J, Maeder ML, Mali P, et al. Gene targeting of a disease-related gene in human induced pluripotent stem and embryonic stem cells. Cell Stem Cell. 2009;5:97-110.

59. Hockemeyer D, Soldner F, Beard C, et al. Efficient targeting of expressed and silent genes in human ESCs and iPSCs using zinc-finger nucleases. Nat Biotechnol. 2009;27:851-857.

60. Orkin SH, Higgs DR. Sickle cell disease at 100 years. Science. 2010;329: 291-292.
Journal of Blood Medicine

\section{Publish your work in this journal}

The Journal of Blood Medicine is an international, peer-reviewed, open access, online journal publishing laboratory, experimental and clinical aspects of all topics pertaining to blood based medicine including but not limited to: Transfusion Medicine; Blood collection, Donor issues, Transmittable diseases, and Blood banking logistics; Immunohematology; Artificial and

\section{Dovepress}

alternative blood based therapeutics; Hematology; Biotechnology/nanotechnology of blood related medicine; Legal aspects of blood medicine; Historical perspectives. The manuscript management system is completely online and includes a very quick and fair peer-review system. Visit http://www.dovepress. com/testimonials.php to read real quotes from published authors. 